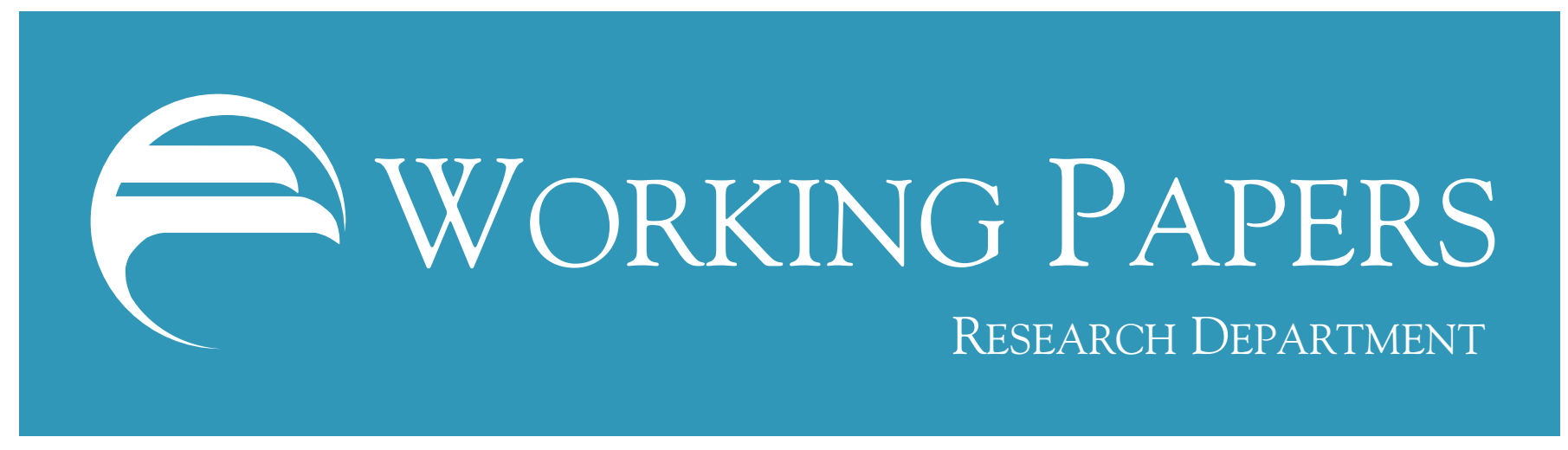

\title{
WORKING PAPER NO. 03-5 \\ HOW STRONG IS CO-MOVEMENT IN EMPLOYMENT OVER THE BUSINESS CYCLE? \\ EVIDENCE FROM STATE/INDUSTRY DATA
}

Gerald A. Carlino

Federal Reserve Bank of Philadelphia

Robert H. DeFina

Economics Department

Villanova University

March 2003

\section{FEDERAL ReSERVE BANK OF PHILADELPHIA}

Ten Independence Mall, Philadelphia, PA 19106-1574• (215) 574-6428• www.phil.frb.org 


\section{Introduction}

The tendency of output and employment to co-move positively across broad industry categories is a well-documented feature of national business cycles. ${ }^{1}$ Much less is known, however, about the degree of co-movement at the state and regional levels. Local economies are clearly influenced by aggregate and industry-specific shocks. Moreover, propagation mechanisms that transmit shocks across industries at the national level also operate at the sub-national level. ${ }^{2}$ But influences specific to regions and to particular industries within regions can intervene to alter cyclical behavior, such as the extent of co-movement, relative to that observed for industries at the national level. Indeed, the notions of a "rolling recovery" and of a "bi-coastal recession" used in journalistic discussions suggest an awareness that the magnitude and timing of fluctuations in business activity vary across regions.

In this study, we quantify the degree of co-movement in quarterly one-digit industrial employment within and across states and regions. The analysis spans the years 1942 to 1995 , a period that includes 10 national business cycles as defined by the National Bureau of Economic Research (NBER). The measurements are important for several reasons. First, they represent basic stylized facts needed for regional businesscycle analysis. Indeed, they help us to understand whether local economies experience what are commonly thought of as business cycles. While previous studies have explored the sources of shocks to regional economies and the presence of regional spillovers, they have offered little evidence on the strength and direction of industry co-movement that

\footnotetext{
${ }^{1}$ Relevant theoretical and empirical analyses include Long and Plosser (1983, 1987), Startz (1989), Cooper and Haltiwanger (1990), Murphy, Shleifer, and Vishny (1989) and Shea (1996, 2002).
} 
results. ${ }^{3}$ Second, the estimates allow a comparison with the degree of co-movement at the national level and so give insight into the importance of national versus regionspecific shocks in local business activity. Third, they provide data for an investigation into the reasons for regional differences in co-movement.

Two things are needed to study industry co-movement: a measure of the businesscycle component of the data and a definition of co-movement. The business-cycle components of the employment data are extracted using a band-pass filter to remove frequencies shorter than eight quarters and longer than 32 quarters, a standard approach in the literature describing business cycles [see, e.g., Burns and Mitchell (1946), McCarthy and Steindel (1997), Baxter and King (1999), and Christiano and Fitzgerald (1998)]. The measure of co-movement used in this study consists of the dynamic correlation between the band-passed series, as described in Croux, Forni, and Reichlin (2001) [hereafter CFR (2001)]. CFR (2001) refer to this measure as cohesion and argue that it is better suited to gauging the degree of co-movement than are other commonly used techniques such as squared coherence, co-integration, and common features.

The study reports six main findings. First, the distribution of bi-variate cohesions for all state/industry pairs is widely dispersed but generally positive, confirming the idea of cross-industry co-movement of employment. However, the distribution masses around a relatively low value, suggesting considerable idiosyncratic variation in state industrial employment cycles. Second, state/industry cohesion has risen over time. Possible reasons include technical innovations in communication and transportation technologies

\footnotetext{
${ }^{2}$ Among these are demand and input-output relationships among industries, imperfect competition and inventory holdings, and external economies of scale.

${ }^{3}$ Clark and Shin (2000) provide a thorough review of relevant literature.
} 
that have helped to transmit shocks across states and industries to a greater extent than previously. Third, cohesion increases with spatial aggregation. That is, cohesion of industry cycles at the national level and in the eight BEA regions is substantially greater than at the state level. Fourth, the degree of industry co-movement is sensitive to the chosen periodicity of the data. Cohesion indexes computed using business-cycle frequencies of employment are substantially larger than those based on log firstdifferences of employment. They also have a completely different pattern of relative magnitudes across states. Thus, log first-differenced data, which are typically used in regional business-cycle analysis, can be ill-suited to capturing business-cycle dynamics for local economies. Fifth, cohesion is much greater among state/industry pairings than across different industries within a state. For example, the degree of co-movement between manufacturing employment in different states is substantially greater than between manufacturing employment and employment in other industries within a state. Finally, we explore some possible reasons for differences in cross-state variation in industrial cohesion. We find that cross-state variation in industry cohesion reflects differences in the strength of input-output linkages within each state, the different state effects of monetary policy actions, and the varying extent of industrial concentration. No state-level support is found for Shea's (1996) hypothesis that industries that locate together co-move to a greater extent than do those that are more spatially diffused. 


\section{Literature Review}

Much of the research on regional business-cycle theory and measurement has explored whether economic activity in one region affects that of another region. ${ }^{4}$ This is especially true of more recent analyses based on VAR techniques and dynamic factor models that seek to identify how economic shocks to a region or an industry within a region translate into variability in other industries and regions [e.g., Norrbin and Schlagenhauf (1988), Sherwood-Call (1988), Altonji and Ham (1990), Blanchard and Katz (1992), Cromwell (1992), Coulson (1993), Coulson and Rushen (1995), Carlino and DeFina (1995), McCarthy and Steindel (1997), Kuttner and Sbordone (1997), Clark (1998), and Carlino, DeFina and Sill (2000)]..$^{5}$ The evidence provided, such as impulse response functions and variance decompositions, tends to indicate the existence of important spillovers but does not quantify the extent of industry co-movement.

Studies on industry co-movement at the national level are most directly related to the present paper. These include Long and Plosser (1987), Cooper and Haltiwanger (1990), Christiano and Fitzgerald (1998), CFR (2001), and Shea (1996, 2002).

Long and Plosser (1987) find that average pairwise correlations for monthly output growth in 13 manufacturing sub-sectors are positive and range between 0.16 and 0.59. CFR (2001) analyze the degree of co-movement in personal income of the 50 U.S. states plus Washington D.C. and in the GDP of 17 western European nations. They use

\footnotetext{
${ }^{4}$ Early work dates back to McLaughlin (1930) and continues with Vining (1949), Borts (1960), and Syron (1978). Domazlicky (1980) surveys much of this literature and concludes that "all of the early authors used fairly simple methodology....and...none of these studies was comprehensive as most were limited to a single state or a few selected cities."

${ }^{5}$ Clark and Shin (2000) provide an extensive review of the recent literature. Co-movements between series have also been studied using rank-reduction techniques, such as co-integration [Engle and Granger (1987)], codependence [Gourieroux and Peaucelle (1992)], common features [Engle and Kozicki, (1993)], and
} 
annual data and measure the co-movement at various cyclical frequencies using dynamic correlations. For business-cycle frequencies, they find that correlations of personal income are relatively high -- 0.8 for states and 0.9 for broad regions. Correlation is noticeably lower ( 0.4 to 0.5 ) for European countries and those in the European Monetary Union.

Cooper and Haltiwanger (1990) make an important conceptual point that positive co-movement in industry output or income does not necessarily imply positive comovement in industry employment. ${ }^{6}$ Nonetheless, they estimate contemporaneous correlations of quarterly de-trended log employment hours for eight one-digit SIC groupings and find that all but two of the 29 correlations are positive. The positive correlations range from 0.08 to 0.81 , with a mean value of 0.4 .

Christiano and Fitzgerald (1998) also document business-cycle co-movement in hours worked across a range of disaggregated industry categories. They gauge the extent of co-movement using squared coherence, calculated as the $\mathrm{R}^{2}$ from a regression of the business-cycle component of a sector's monthly hours on the business-cycle component of total hours worked at lags 0, 1, and -1. Christiano and Fitzgerald (1998) estimate a mean for all industrial correlations of 0.55 , and a mean of 0.68 after excluding the mining, tobacco, and petroleum industries. They conclude that a substantial amount of industry co-movement is present in the data. Shea (2002) computes the average pairwise correlation of annual employment growth for 126 three-digit manufacturing industries to

common cycles [Vahid and Engle (1993)]. For several reasons, these approaches are less well-suited to the task at hand.

${ }^{6}$ For example, certain real business-cycle models, such as that described in Long and Plosser (1983), predict positive co-movement in output but negative co-movement in employment. The negative employment co-movement arises because of substitution of labor across industrial sectors over a cycle. 
be 0.341 . He finds the corresponding values for output and value added to be 0.284 and 0.228 , respectively.

\section{Empirical Analysis}

As indicated earlier, the degree of co-movement is quantified using the cohesion index of CFR (2001). The measure constitutes the dynamic correlation between the business-cycle components of industry employment series. The band-pass filter used to isolate business-cycle frequencies in the data is two-sided and symmetric. Following Baxter and King (1999), a window of 25 quarters is used, with 12 leading and 12 lagging periods.

Using the filtered data, both bi-variate and multi-variate dynamic correlations are calculated between the relevant series. Bi-variate dynamic correlations quantify the extent of cohesion between two series at business-cycle frequencies. Multivariate cohesion indexes are computed as a weighted sum of the distinct bi-variate dynamic correlations. Assuming that the weights are normalized so that they sum to one, and given that the dynamic correlation coefficients vary between -1 and 1 , both the bi-variate cohesions and multivariate cohesion indexes must also vary between -1 and 1 . Multivariate indexes will be used to make cross-state comparison of overall business-cycle cohesion.

The study uses a new data set on quarterly employment for each of eight one-digit industries by state: mining, construction (const), manufacturing (mfg), transportation, communications, and public utilities (tpu), wholesale and retail trade (w/r trade), finance, insurance, and real estate (fire), services (serv), and government (govt). Information for 
the majority of states extends back to 1939 , much earlier than previously available data. ${ }^{7}$ In total, 38 of the 48 states have complete data for all industries, while the remaining 10 states are missing early data for one or more industries. ${ }^{8}$ Complete industry data for all states exist from 1982:1 on.

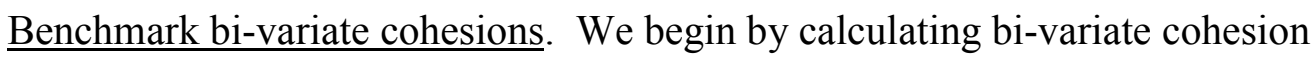
values for all state/industry pairs, using only the 38 states for which data on all 8 industries are available. Thus, there are 304 state/industry pairs and 62,185 distinct bivariate cohesion values. Observations on the business-cycle component of the data cover the $1942: 1$ to $1995: 4$ period. $^{9}$

To provide the most comprehensive view of business-cycle co-movement, bivariate cohesion values for each of the 62,185 distinct state/industry pairs were calculated. Thus, each industry within each state is treated as a separate and unique industry cycle. Figure 1a summarizes the resulting distribution.

A large majority ( 83 percent) of the cohesion values are positive, consistent with previous findings based on national data. Yet, most of the positive values also have relatively small magnitudes; the mean is 0.29 and the median is 0.33 . These summary values are below the means of 0.4 and 0.6 for industry employment hours presented in Cooper and Haltiwanger (1990) and Christiano and Fitzgerald (1998), respectively, and

\footnotetext{
${ }^{7}$ The data for this study are not publicly available and were obtained by special order from the U.S. Labor Department. The study uses employment rather than output because gross state product is only available annually and not before 1963. Also, as mentioned previously, employment can exhibit a pattern of comovement quite different from output. Thus, employment is of independent interest.

${ }^{8}$ The 10 are Connecticut, Delaware, Illinois, Massachusetts, Michigan, Maine, Minnesota, Maryland, Rhode Island, and Utah.

${ }^{9}$ Three years of raw employment data are lost at the beginning and end of the sample because of the filtering.
} 
are well below the mean of 0.8 for state personal incomes found in CFR (2001). ${ }^{10}$ Thus, the industry/state cycles are less synchronized than industry cycles at the national level.

A question remains about how representative the 38 states comprising the sample are. Insight is obtained by comparing the distribution of cohesions for the 38-state sample with that of the 48-state sample for the period 1985:1 to $1995: 4$, the time span for which all states have complete industry data. The comparisons are presented in Figure 1b. To eliminate differences in the shapes of the distributions due simply to the larger number of state industry pairs for the 48 -state sample, the frequencies for the 38 -state sample were proportionately increased so that the total number of cohesions equals that for the 48-state sample.

The median for each sample is about 0.26 , with a sizable majority of cohesion values in each sample being positive. Indeed, the distributions appear virtually identical, and it is reasonable to conclude that the sample of 38 states fairly represents the sample of 48 states. Given that the 38-state sample permits the study of a considerably longer time period (an additional 40 years), the remainder of the analysis focuses on these states.

The impact of regional aggregation. An issue of interest in business-cycle analysis is the degree to which industry co-movement changes as the level of regional aggregation changes. ${ }^{11}$ As noted above, each state/industry cycle has a noticeable idiosyncratic component. Regional aggregation could average out some of these nonsystemic movements, resulting in greater measured cyclical cohesion for broader areas.

\footnotetext{
${ }^{10}$ As will be discussed below, the differences are due mainly to the added disaggregation. That is, the present study compares all industry/state pairs instead of just comparing industry pairs or state pairs.
} 
To examine how the distribution of cohesions changes with the level of regional aggregation, industry employment cycles are recalculated after aggregating each industry employment series across the eight BEA regions and all 48 states. Because we analyze regions, it is important to use the sample for all 48 states to arrive at correct regional definitions. Thus, for this analysis, we restrict attention to the period from 85:1 to 95:4 for which data on employment are available for all 48 states. Three levels of regional aggregation are considered: states (as before); eight BEA regions; and the nation. That is, cohesions are calculated for each industry/region pair (e.g., mining in the Far West region and services in the Mideast region), and for national industry pairs (e.g., national mining employment and national services employment).

The resulting distribution of cohesion values for region/industry pairs is presented in Figure 2. The distribution of region/industry pair cohesions shifts rightward relative to the state/industry pair distribution. The median cohesion value for the region/industry distribution is 0.41 , or 25 percent above the 0.33 median for the state/industry pair distribution. The percent of positive cohesions is 75 percent, a bit below that of the state/industry pairs.

The distribution of aggregate industry cohesions, shown in Figure 3, is similar to that for region/industry pairs. The mean cohesion value for the aggregate industry distribution is 0.39 , while the percent of positive cohesions is roughly the same as for state/industry pairs. In sum, co-movement appears to increase as one moves from states to broad regions, although further aggregation to the national level has little effect.

\footnotetext{
${ }^{11}$ See, for example, Carlino, DeFina, and Sill (2001). Horvath and Vebrugge (1996) explore the importance of aggregation across detailed industry sectors for the analysis of business cycles.
} 
Business-cycle versus high-frequency co-movement. Previous studies on regional business-cycle dynamics have been based on log first-differences of data [e.g., Sherwood-Call (1988), Cromwell (1992), Coulson (1993), Coulson and Rushen (1995), and Carlino and DeFina (1995)]. These high-frequency changes are outside what is usually characterized as business-cycle movements. How significant is the data filter for conclusions about industry co-movement? Figure 4 contains frequency distributions of cohesion values based on the business-cycle component of the employment data and on quarterly $\log$ first-differences. Both are computed using the 38 states for which full samples are available. The median value for state cohesions based on first-differences is 0.13, compared to a median of 0.33 for the business-cycle frequency. Moreover, only 15 percent of the cohesion values exceed 0.3 and only 1.5 percent exceed 0.6 . The comparable fractions for the business-cycle components of employment are 53 percent and 16.8 percent.

Not only are the cohesion values for the log first-differenced series on average lower, they also display a different rank ordering across states. A calculated rank-order statistic reveals that the state orderings are significantly different at the 5 percent level. Thus, conclusions about the degree of cohesion seem to depend critically on the frequency band of the data studied.

Multivariate cohesion indexes for states. An issue of importance and interest to regional economics is the way in which business-cycle activity varies over space. To address the issue, within-state multivariate cohesion indexes are computed to provide evidence on cohesion across industry cycles by state. These indexes are weighted averages of the bi-variate cohesions for the eight industries within each state. Consistent 
with CFR (2001), the weights are the products of the employment levels for each industry in the bi-variate correlation, normalized so that the weights sum to one. ${ }^{12}$

In Figure 5a, the multivariate cohesion indexes are given for each state, with each state's value identified by the state's abbreviation. The state cohesion values are fairly dispersed. As with the bi-variate cohesion values, the within-state multivariate values are relatively small. All cohesion indexes are positive, ranging from around 0.13 (Nebraska) to 0.45 (Kentucky). The median cohesion value is about 0.31 .

Figure $5 \mathrm{~b}$ graphs the same values as in Figure 5a, except that it identifies each state by its BEA region. Interestingly, the state values tend to cluster on either side of the median of 0.31 by region. For example, nine of the 11 southeastern states have cohesion values above the median, as do all the Great Lakes states. The clear majority of states in the Plains and Southwest, by contrast, have cohesion values below the median. Possible factors that help to explain the spatial distribution of the cohesions are identified below.

Changes in cohesion over time. The U.S economy has experienced a variety of structural shifts during the past 60 years. These include employment shifts from goodsproducing industries to service-producing industries, proportionate shifts in consumer spending away from nondurables toward services (and to a far lesser extent toward durables), technological innovations in banking, financial markets, and inventory control, and the introduction of new macro policies and procedures (e.g., variations in the targets of monetary policy and the increased reliance on automatic stabilizers). Any and all such developments can affect the magnitude, duration, and cohesion of cycles in economic

\footnotetext{
${ }^{12}$ Diagonal elements of the correlation matrix are excluded for purposes of the calculation. See the discussion in CFR (2001), p. 236.
} 
activity. A relevant question is: Has the extent of cohesion in industry employment cycles changed over time?

This question is answered in two ways. The first concentrates solely on the interperiod change in the distribution of state/industry pair cohesions. Doing so isolates any changes in the relationships between the cycles in each industry pair. Figure 6 shows the distributions for two sub-periods that essentially divide the sample in half: 1942:1 to 1968:4 and 1969:1 to 1995:4. The figure shows that the distribution has moved rightward over time, although not dramatically so. The median cohesion value increased from 0.35 during the period 1942-68 to 0.4 during the period $1969-95$ because of a reduction in the number of negative cohesion values. Overall, the distributions appear quite similar.

The second answer examines how the multivariate state cohesion values have evolved. Unlike the bi-variate distribution, the distribution of multivariate indexes can change either because the underlying bi-variate distribution changes or because the weights used to combine state/industry pairs into state values change. Recall that the weights for the multivariate index are the products of the employment levels for the two state/industry series comprising each bi-variate pairing. Thus, shifts in the industrial composition of employment and the relocation of employment across states can both affect the distribution of state multivariate cohesions.

The distributions for the multivariate state cohesion values for the two subperiods are displayed in Figures 7a (1942-68) and 7b (1969-95). The results suggest the distribution became less disperse. For instance, the coefficient of variation among the cohesion values fell from 0.51 in the early period to 0.44 in the later period. The 
particulars of the shift caused the median cohesion value to rise, from 0.21 in the early period to 0.26 in the later period.

Cross-state cohesion for major industries. An alternative way of characterizing co-movement is the cohesion of employment growth in a given industry across states. That is, to what degree does the cycle in manufacturing employment in Kansas correspond to the cycle in manufacturing employment in the other states?

Figure 8 displays the multivariate cohesion index values for each of the eight industries under examination. The weights for each multivariate industry index are the products of the employment levels for state pairs in the bi-variate correlation, normalized so that the weights sum to one. Two aspects of the results merit notice. First, there is considerable variation in the degree of co-movement across industries. The businesscycle component of manufacturing employment shows a high degree of cohesion across states (0.82), while that of mining employment displays about half as much (0.44). Cohesion is relatively highest in the construction, manufacturing, trade, and government sectors; cohesion is relatively low in the services sector.

Second, and perhaps not surprisingly, the degree of cohesion for a given industry across states is considerably higher than that for cohesion across different industries within a state. For example, the business-cycle components of manufacturing employment in different states co-move substantially more than do the cyclical components of manufacturing and other industries within a given state. The median cross-state industry cohesion is about 0.66 for the full sample, compared to a median of 0.31 for the bi-variate state/industry pair cohesions. 


\section{Why Has Cohesion Varied Across States?}

In this section, we examine possible determinants of measured cross-state differences in multivariate cohesion indexes. Studies explaining co-movement at the national level have emphasized both the types of shocks hitting industries as well as the propagation mechanisms that transmit the shocks across industries. Certain aggregate shocks, such as changes in monetary policy, can affect all industries, although perhaps by different amounts. These disturbances by their nature cause industry co-movement. Other industry-specific shocks, such as technology changes, can also induce comovement, either because the shocks cause sympathetic changes in other industries' outputs due to input-output linkages or demand spillovers [see, e.g., Long and Plosser (1983, 1987), Cooper and Haltiwanger (1990), Startz (1989), and Murphy, Shleifer, and Vishny (1989)].

To examine the possible impact of these types of factors, we estimated the following cross-section regression model:

$$
C_{i}=\alpha_{0}+\alpha_{1} I O_{i}+\alpha_{2} M_{i}+\alpha_{3} I S_{i}+\sum_{j=1}^{7} \beta_{j} R_{j}+\varepsilon_{i}
$$

where $C_{i}$ is the multivariate cohesion value; $I O_{i}$ measures the strength of interindustry input-output relationships in state $\mathrm{i} ; M_{i}$ captures the impact of monetary policy actions on state $\mathrm{i} ; S_{i}$ is an index of industrial specialization for state $\mathrm{i}$; and $R_{j}$ is a dummy variable indicating in which of the eight BEA region state $i$ is located (the Far West region is excluded). The dummy variables are used to account for unmeasured region-specific fixed effects. 
The strength of production relationships, $I O$, is calculated by summing one-digit input-output total requirements coefficients from the national input-output table across the columns. This yields the total importance of each industry's output as an input into all other industries. Each industry sum is then weighted by the fraction of industry employment in state total employment, and a weighted average for each state is calculated. ${ }^{13}$ The stronger the input-output linkages in a state, the higher the degree of industry co-movement in a state there should be, as a shock to a particular industry is transmitted more strongly via trade to other industries in a state.

Estimates of the state-level effects of monetary policy are taken from Carlino and DeFina (1999). ${ }^{14}$ They found substantial differences in state responses to monetary policy shocks during the period 1958-92. The stronger the influence of monetary policy on a state, the more cohesive state industry cycles should be. As an aggregate shock, the policy action should drive all industries within a state in the same direction with roughly similar timing, although by different magnitudes.

The index of industry specialization, $I S$, is calculated as:

$$
I S_{i}=\left(\sum_{j=1}^{8}\left(s s_{i, j}-n s_{j}\right)^{2}\right)^{1 / 2},
$$

where $s s_{i, j}$ is the share of employment in state $i$ in industry $j$, and $n s_{j}$ is the share of employment in industry $j$ for the 38-state aggregate [Malizia and Ke (1993)]. Thus, the index measures the extent to which a state is less diversified (more specialized) than the

\footnotetext{
${ }^{13}$ For example, we summed the coefficients indicating the contribution of manufacturing to each of the other industries. We did the same for construction, services, etc. We then weighted each of the sums by the appropriate employment fraction in, say, Alabama and added them together to get a weighted sum. We did this for all states.
} 
38-state aggregate. The more specialized a state's industrial structure, the greater is the expected degree of cohesion. A state dominated by one industry, for example, will show considerable cohesion, since shocks to the other industries will have a relatively small overall impact.

The results of the estimation are displayed in Table 1. The variables have the expected signs, and each is statistically significant at the 10 percent level or more. In terms of elasticities, state cohesion indexes are most sensitive to changes in the weighted input-output coefficient (elasticity $=0.63)$, followed by monetary policy (elasticity $=$ 0.31). Cohesion is least sensitive to changes in the degree of industry specialization (elasticity $=0.07)$

We also examined a theory offered by Shea $(1996,2002)$ that industries that tend to locate in the same cities tend to co-move at the national level. Shea (1996) offers empirical support for the basic proposition by creating two variables, which he calls CORRCIT $_{\text {ik }}$ and CORREMP ${ }_{\text {ik. }}$ CORRCIT $_{\text {ik }}$ captures the spatial correlation between industries $\mathrm{i}$ and $\mathrm{k}$ in a given city. The variable is computed as the dot product of the industries' vectors of employment shares by city, normalized by each industry's spatial concentration. CORREMP ${ }_{i k}$ is the dynamic correlation of employment growth between industries $\mathrm{i}$ and $\mathrm{k}$ (Shea uses annual employment growth as his measure of business-cycle variation). Shea regresses CORREMP ${ }_{\mathrm{ik}}$ on CORRCIT $_{\mathrm{ik}}$ and finds that the estimated coefficient on CORRCIT $T_{\mathrm{ik}}$ is positive and highly significant.

\footnotetext{
${ }^{14}$ Carlino and DeFina (1999) estimate 48 state-specific VARs, which include employment growth and the change in the federal funds rate, among other variables. The state-specific monetary policy effect equals the eight-quarter impulse response of employment growth to a federal funds rate shock.
} 
We replicated Shea's methodology using the state data, measuring CORREMP ${ }_{\mathrm{ik}}$ both with quarterly employment growth and with the business cycle components of industry employment. In each case, the coefficient on $\mathrm{CORRCIT}_{\mathrm{ik}}$ is positive but insignificant at standard levels. The $\mathrm{R}^{2}$ for each equation is also smaller than Shea found. Thus, the sorts of forces that Shea finds working at the city level appear not to operate at the state level.

\section{Conclusion}

In this paper we measure the degree of business-cycle co-movement in quarterly industry employment at the state and regional levels. The analysis covers the years 1942 to 1995 . We find that the distribution of bi-variate cohesions for all state/industry pairs is widely dispersed but generally positive. However, the distribution masses around a relatively low value, between 0.2 and 0.3 , suggesting a great deal of idiosyncratic variation in industrial cycles. There is, however, much greater cohesion across states for a given industry than across different industries within a state. Interestingly, the cohesion of industry cycles at the national level and in the eight BEA regions is substantially greater than that within states. This finding suggests that the impact of idiosyncratic shocks to industries within a state is diminished, as these shocks tend to offset each other as the level of spatial aggregation increases.

An investigation into the sources of cross-state variation in cohesion reveals that important determinants include the strength of input-output linkages within each state, the different effects of monetary policy actions on each state's employment, and the degree of industrial diversity within a state. We find no state-level support for Shea's (1996) 
hypothesis that industries that locate together co-move to a greater extent than do those that are more spatially diffused. 


\section{References}

Altonji, Joseph G., and Ham, John C. "Variation in Employment Growth in Canada: The Role of External, National, Regional, and Industrial Factors," Journal of Labor Economics, 8 (1990), pp. 198-236.

Baxter, Marianne, and Robert King. "Measuring Business Cycles: Approximate BandPass Filters for Economic Time Series, ” Review of Economics and Statistics, 81 (1999), pp. 575-93.

Blanchard, Olivier J., and Lawrence F. Katz. "Regional Evolutions," Brookings Papers on Economic Activity 1 (1992), pp. 1-61, with discussions.

Borts, George. "Regional Cycles of Manufacturing Employment in the U.S., 1914-1953," Journal of the American Statistical Association 55 (1960). pp. 151-211.

Burns, A. F., and W. C. Mitchell. "Measuring Business Cycles," National Bureau of Economic Research (1946).

Carlino, Gerald A., and Robert H. DeFina. "Regional Income Dynamics," Journal of Urban Economics 37 (1995), pp. 86-106.

Carlino, Gerald A., and Robert H. DeFina. "The Differential Regional Effects of Monetary Policy: Evidence From the U.S. States," Journal of Regional Science 39 (1999), pp. 339-358.

Carlino, Gerald A., Robert H. DeFina, and Keith Sill. "Sectoral Shocks and Metropolitan Employment Growth,” Journal of Urban Economics 50 (2001), pp. 396-417.

Christiano, Lawrence J., and Terry Fitzgerald. "The Business Cycle: It's Still a Puzzle," Federal Reserve Bank of Chicago Economic Perspectives (Fourth Quarter 1998), pp. 56-83.

Clark, Todd E. "Employment Fluctuations in the U.S. Regions and Industries: The Roles of National, Region-Specific, and Industry-Specific Shocks," Journal of Labor Economics 16 (1998), pp. 202-229.

Clark, Todd, and Kwanho Shin. "The Sources of Fluctuations Within and Across Countries," G.D. Hess and E. von Wincoop (eds.), Intranational Macroeconomics (Cambridge, UK: Cambridge University Press, 2000).

Cooper, Russell, and John Haltiwanger. "Inventories and the Propagation of Sectoral Shocks," American Economic Review, 80 (1990), pp. 170-190.

Coulson, N. Edward. "The Sources of Fluctuations in Metropolitan Areas," Journal of Urban Economics, 33 (1993), pp. 76-94. 
Coulson, N. Edward, and Steven F. Rushen. "Sources of Fluctuations in the Boston Economy," Journal of Urban Economics, 38 (1995), pp. 74-93.

Cromwell, Brian A. "Does California Drive the West? An Econometric Investigation of Regional Spillovers," Federal Reserve Bank of San Francisco Economic Review 2 (1992), p. 15-25.

Croux, Christophe, Mario Forni, and Lucrezia Reichlin. "A Measure of Comovement for Economic Variables: Theory and Empirics," The Review of Economics and Statistics 83 (2001), pp. 232-241.

Domazlicky, Bruce. "Regional Business Cycles: A Survey,” Regional Science Perspectives 10 (1980), pp. 15-34.

Engle, Robert F., and C.W.J. Granger. "Cointegration and Error Correction: Representation, Estimation and Testing," Econometrica 55 (1987), pp. 251-276.

Engle, Robert F., and Sharon Kozicki. "Testing for Common Features," Journal of Business and Economic Statistics 11 (1993), pp. 369-95, with discussions.

Gourieroux, C., and I. Peaucelle. "Series Codependantes: Application a l'Hypothese de Partie du Pouvior d'Achat," l'Actualite Economique 68 (1992), pp. 283-304.

Horvath, Michael T.K., and Verbrugge, Randal. "Shocks and Sectoral Interactions: An Empirical Investigation,” mimeo (June 1996).

Kuttner, Kenneth N., and Argia M. Sbordone. "Sources of New York Employment Fluctuations," Federal Reserve Bank of New York Economic Policy Review 3 (1997), pp. 21-46.

Long, John B., and Plosser, Charles I. "Real Business Cycles," Journal of Political Economy, 91 (1983), pp. 39-69.

Long, John B., and Plosser, Charles I. "Sectoral Versus Aggregate Shocks in the Business Cycle,” American Economic Review 70 (1987), pp.333-336.

Malizia, Emil E., and Shanzi Ke. "The Influence of Economic Diversity on Unemployment and Stability," Journal of Regional Science, 33 (1993), pp. 221235.

McCarthy, Shea (2000) Jonathan, and Charles Steindel. "National and Regional Factors in the Metropolitan Economy," Federal Reserve Bank of New York Economic Policy Review 3 (1997), pp. 5-19. 
McLaughlin, Glenn. "Industrial Diversification in American Cities," Quarterly Journal of Economics 45 (1930), pp. 131-149.

Murphy, Kevin, Andrei Shleifer and Robert Vishny "Building Blocks of Market Clearing Business Cycle Models," in NBER Macroeconomics Annual, edited by Olivier Blanchard and Staley Fischer (1989), pp. 247-301.

Norribin, Stefan C., and Schlagenhauf, Don E. "The Role of International Factors in the Business Cycle," Journal of International Economics, 40 (1988), pp. 84-104.

Shea, John. "Comovement in Cities," Carnegie-Rochester Conference Series on Public Policy, 44 (1996), pp. 169-206.

Shea, John. "Complementarities and Comovements," Journal of Money, Credit and Banking, 34 (2002), pp. 412-433.

Sherwood-Call, Carolyn. "Exploring the Relationship Between National and Regional Economic Fluctuations," Federal Reserve Bank of San Francisco Economic Review (Summer 1988), pp.15-25.

Startz, Richard. "Monopolistic Competition as a Foundation for Keynesian Macroeconomic Models," Quarterly Journal of Economics, 104 (1989), pp. 737 752.

Syron, Richard. "Regional Experience during Business Cycles: Are We Becoming More or Less Alike?," Federal Reserve Bank of Boston New England Economic Review (1978), pp. 25-34.

Vahid, Farshid, and Engle, Robert F. "Common Trends and Common Cycles," Journal of Applied Econometrics 8 (1993), pp. 341-360.

Vining, Rutledge. "The Region as an Economic Entity and Certain Variations to Be Observed in the Study of Systems of Regions," American Economic Review 39 (1949), pp. 89-104. 


\section{Table 1: Determinants of State Multivariate Cohesion Indexes}

\begin{tabular}{|c|c|c|}
\hline Variable & Coefficient & Standard Error \\
\hline Intercept & 0.0260 & 0.1139 \\
\hline Monetary Policy Impact & $0.08616^{* *}$ & 0.036854 \\
\hline $\begin{array}{l}\text { Weighted Input-Output } \\
\text { Coefficient }\end{array}$ & $0.47956^{*}$ & 0.28246 \\
\hline Industry Specialization Index & $0.72807^{*}$ & 0.43362 \\
\hline New England dummy & -0.0307 & 0.0377 \\
\hline Mideast dummy & -0.0564 & 0.0371 \\
\hline Great Lakes dummy & -0.515 & 0.0453 \\
\hline Plains dummy & $-0.1357 * *$ & 0.0567 \\
\hline Southeast dummy & -0.0691 & 0.0522 \\
\hline Southwest dummy & -0.0705 & 0.0458 \\
\hline Rocky Mountain dummy & 0.0272 & 0.0487 \\
\hline Adjusted $\mathrm{R}^{2}$ & 0.48401 & \\
\hline
\end{tabular}

*,** indicates significance at the 10 percent level and 5 percent level, respectively. 
Table 2: Tests of Shea's Hypothesis

(Dependent Variable: CORREMP)

\begin{tabular}{|c|c|c|}
\hline Specification & Coefficient on CORRCIT $^{\mathbf{a}}$ & ${\text { Adjusted } \mathbf{R}^{\mathbf{2}}}$ \\
\hline Band-Pass data & $\begin{array}{c}0.2601 \\
(0.4590)\end{array}$ & 0.0122 \\
\hline First-Difference Data & 0.2517 & 0.0238 \\
\hline
\end{tabular}

${ }^{\mathrm{a}}$ Standard errors are in parentheses below the coefficient estimate. 
Figure 1a: State/Industry Pair Cohesions (38-state sample, 1942:1 to 1995:4)

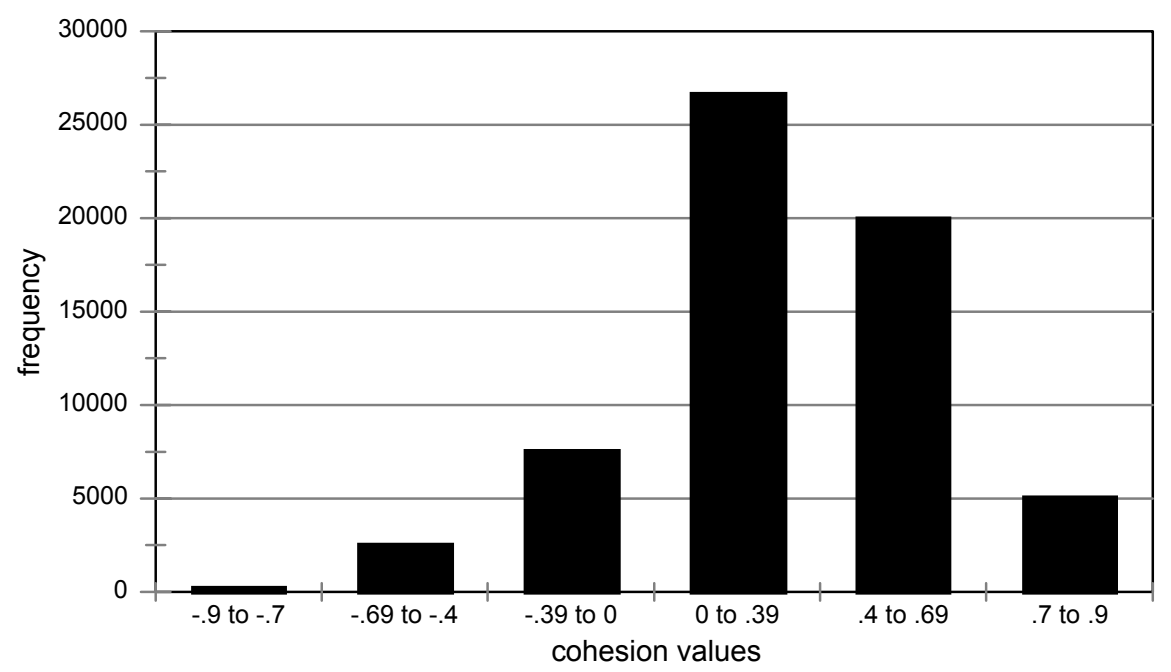

Figure 1b: State/Industry Pair Cohesions (38-state and 48-state sample, 1985:1 to 1995:4)

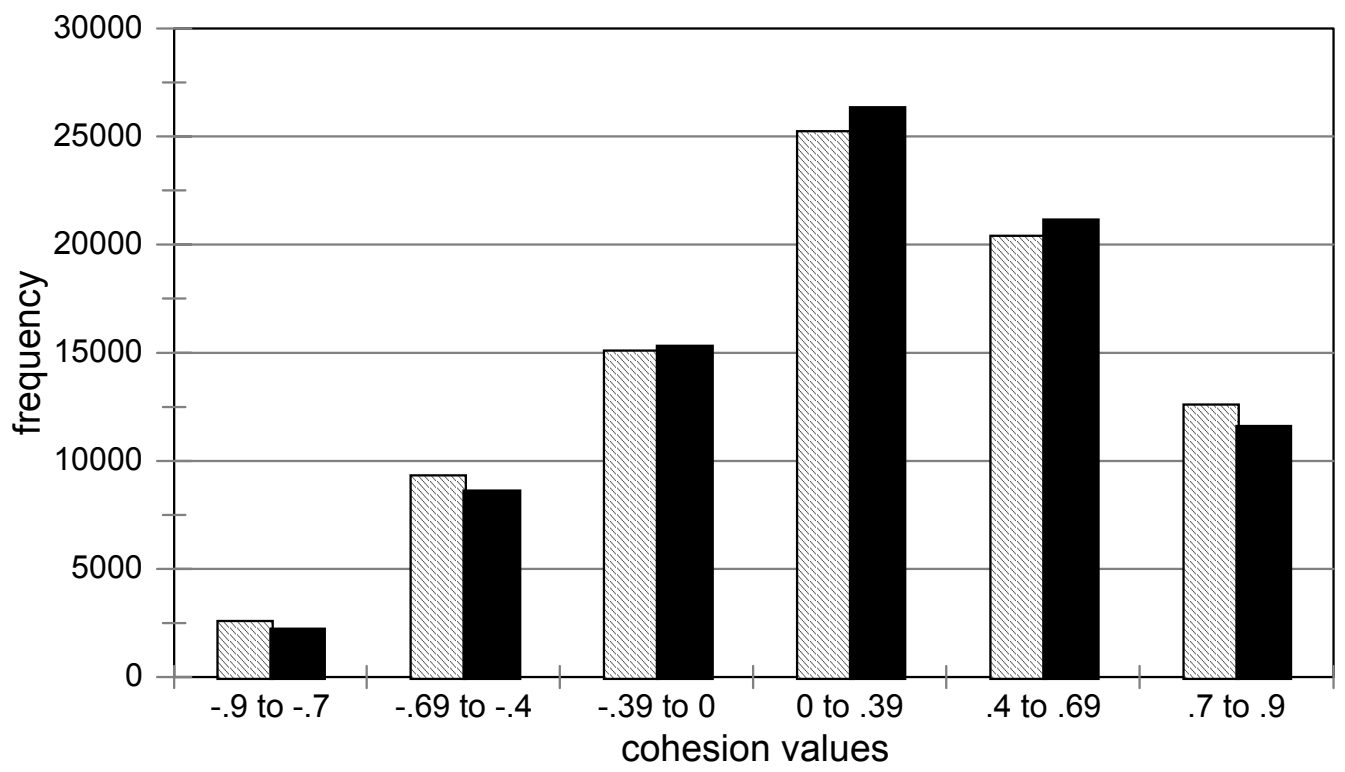


Figure 2: Regional/Industry Pair Cohesions

(BEA regions, 1985:1 to 1995:4)

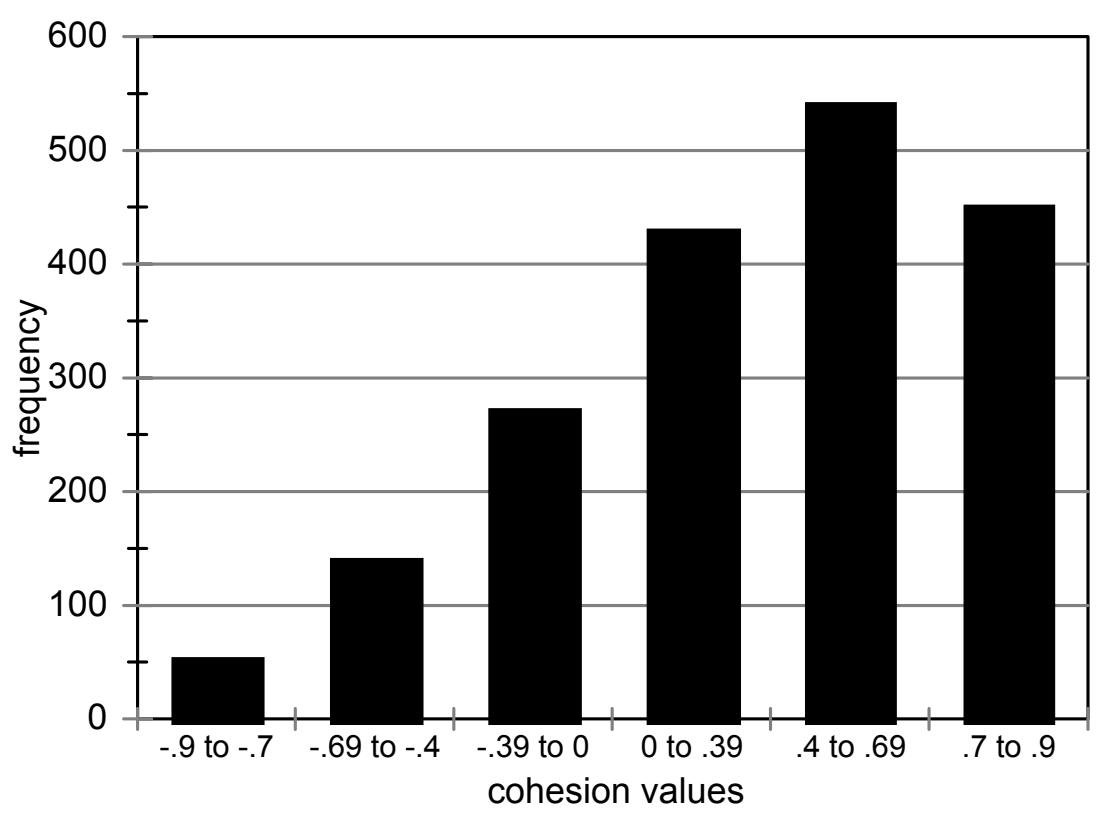

Figure 3: Aggregate Industry Pair Cohesions (1985:1 to 1995:4)

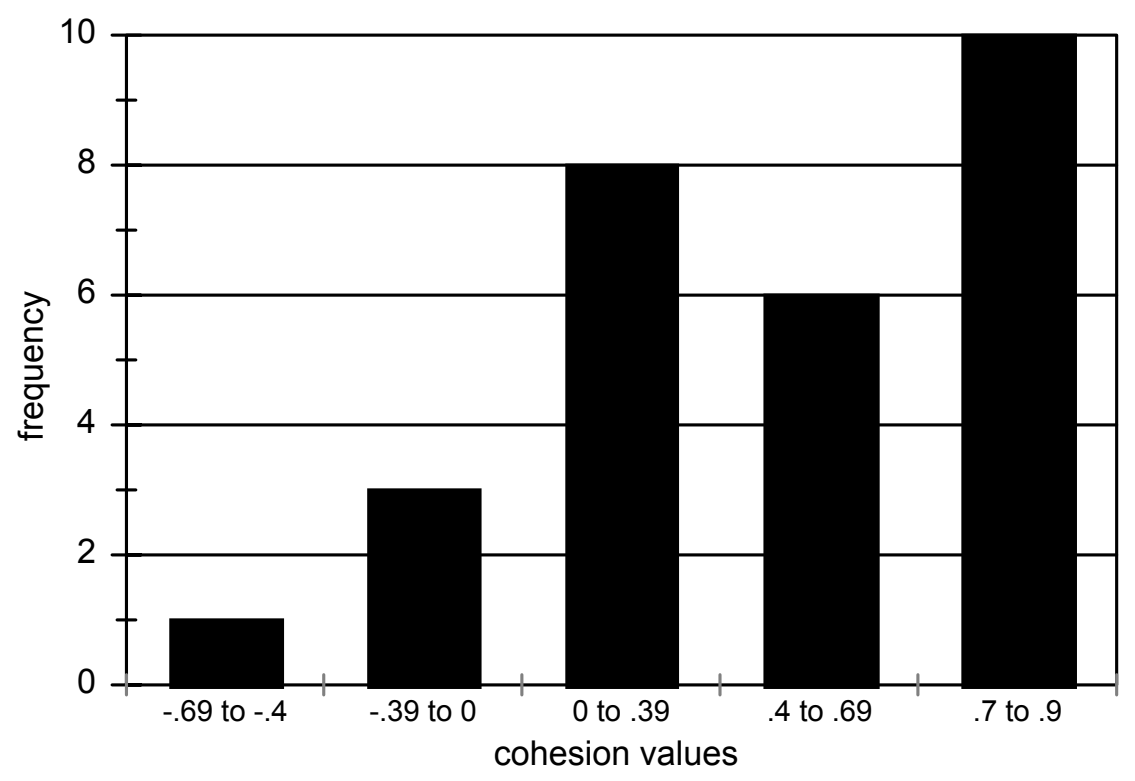


Figure 4: State/Industry Pair Cohesions by Frequency (38-state sample, 1942:1 to 1995:4)

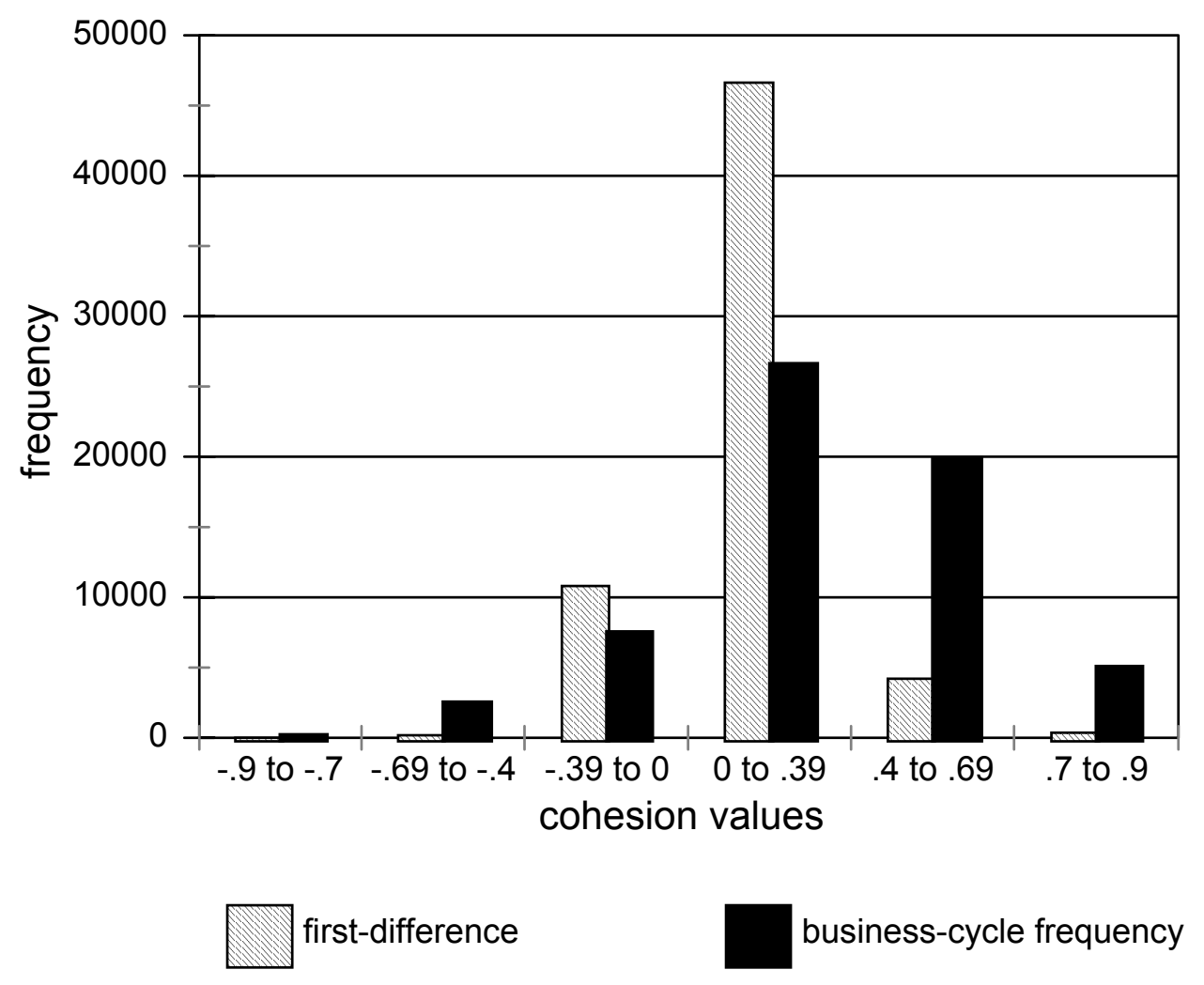


Figure 5a: Multivariate State Cohesion Indexes (38-state sample, 1942:1 to 1995:4)

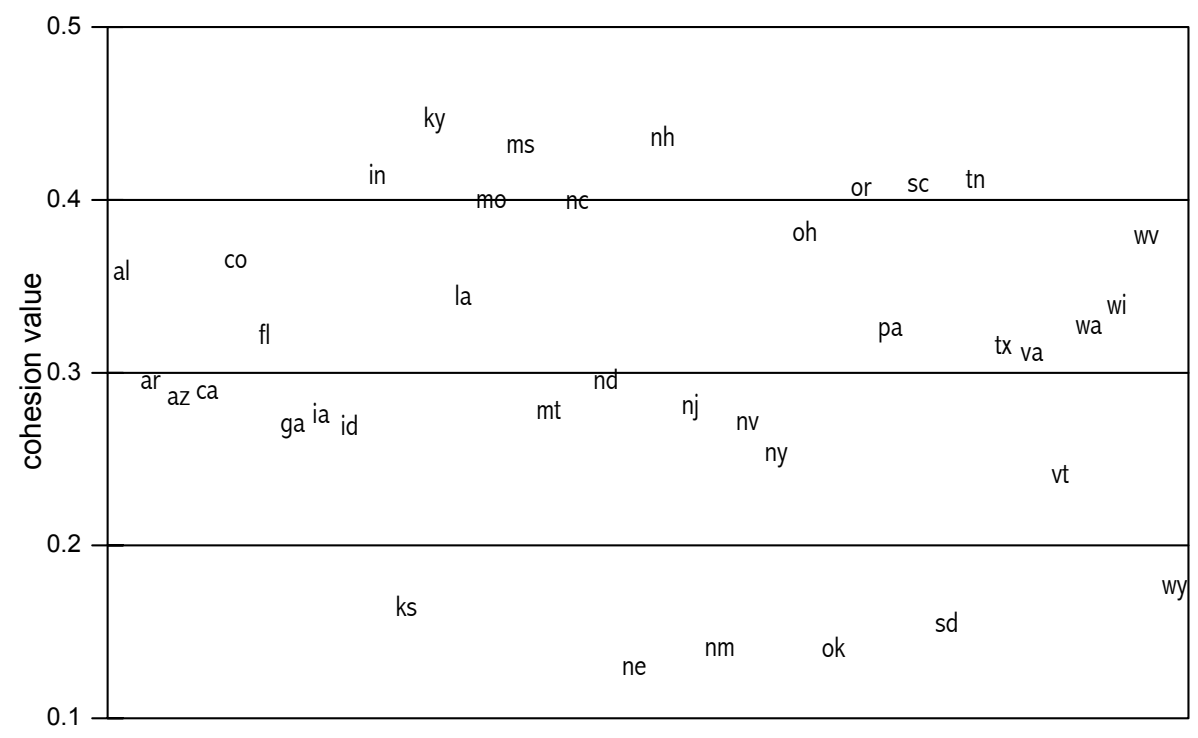

Figure 5b: Multivariate State Cohesion Indexes

(by BEA region of state, 1942:1 to 1995:4)

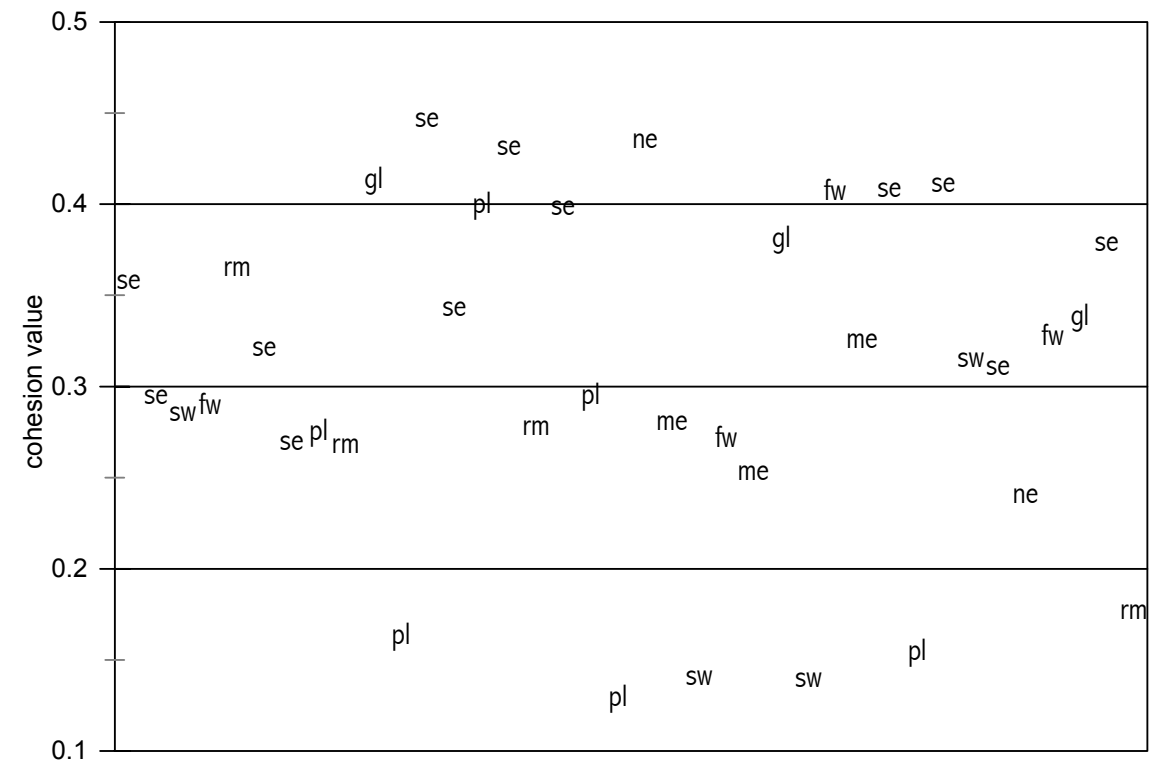


Figure 6: State/Industry Pair Cohesions

(by sub-period)

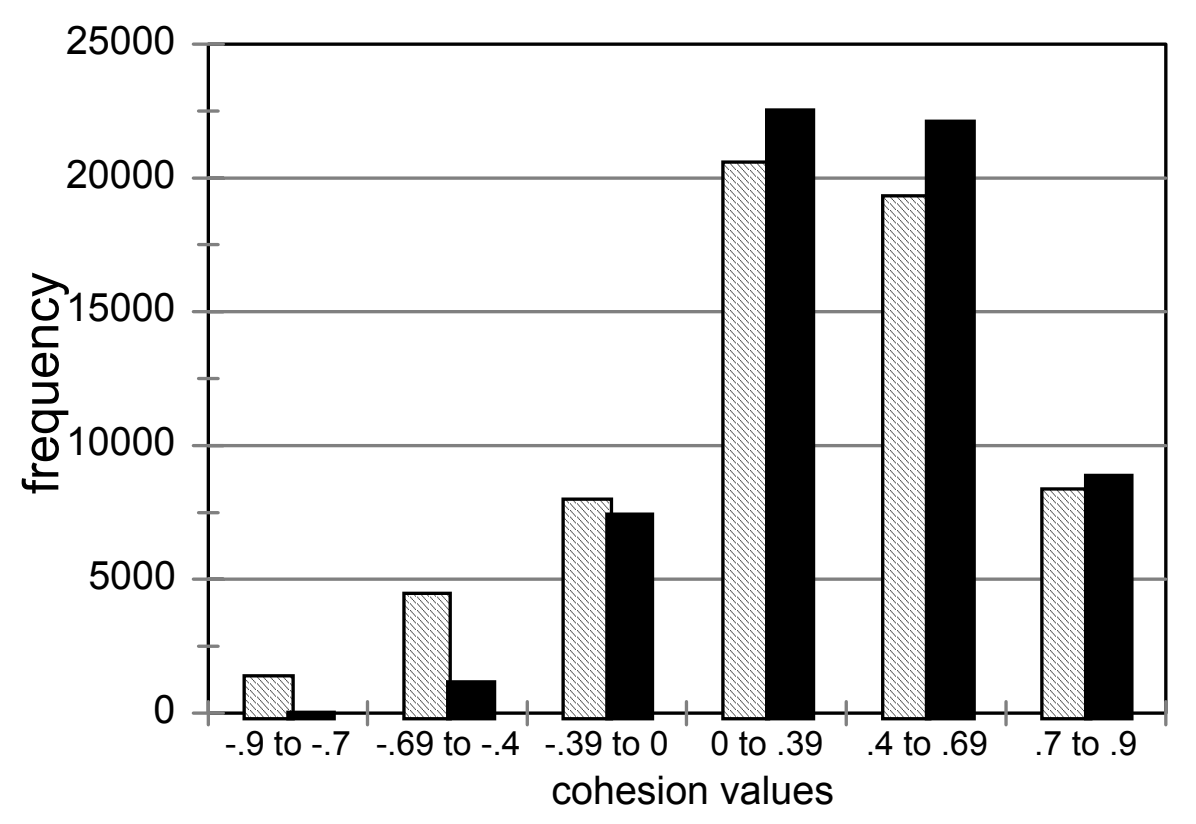

69:1 to $95: 4$ 
Figure 7a: Multivariate State Cohesions (1942:1 to 1968:4)

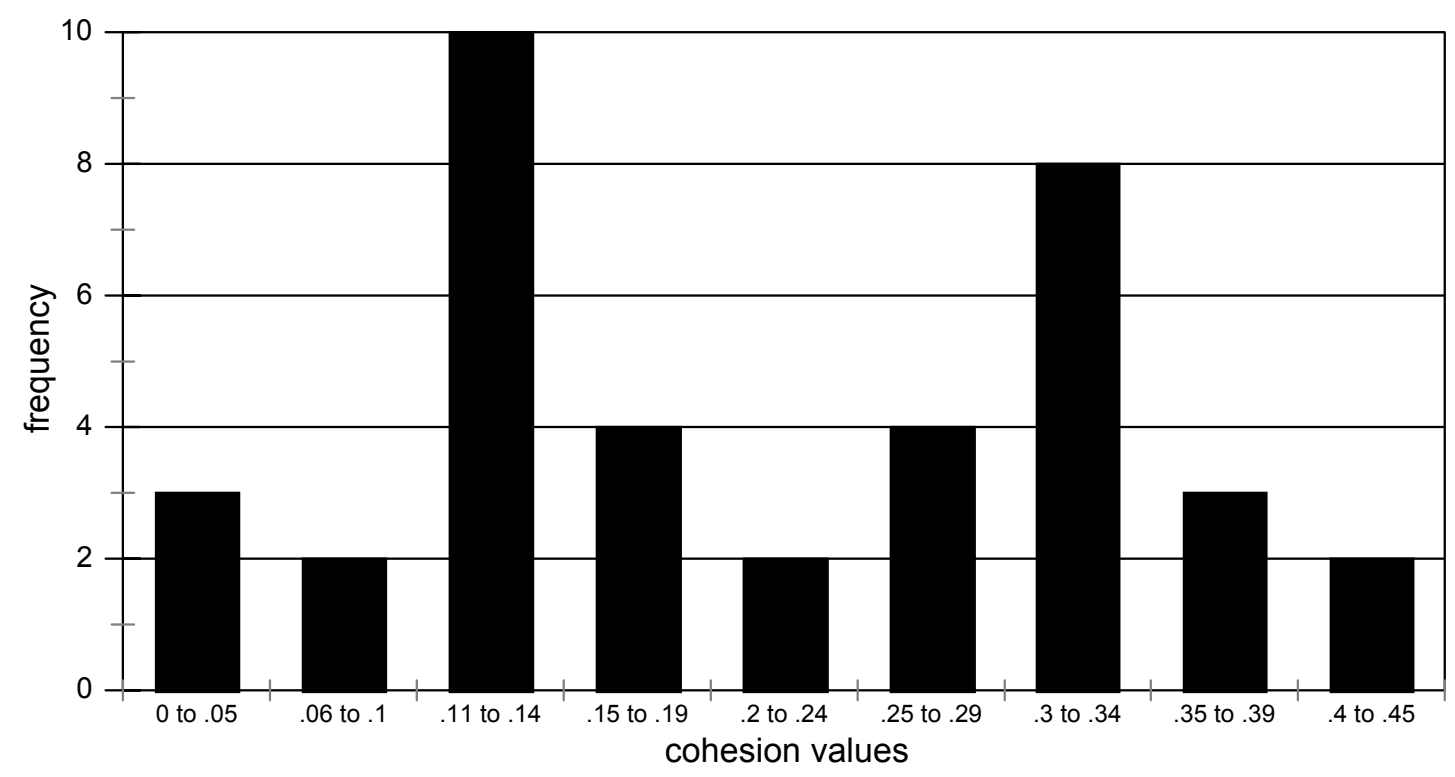

Figure 7b: Multivariate State Cohesions (1969:1 to 1995:4)

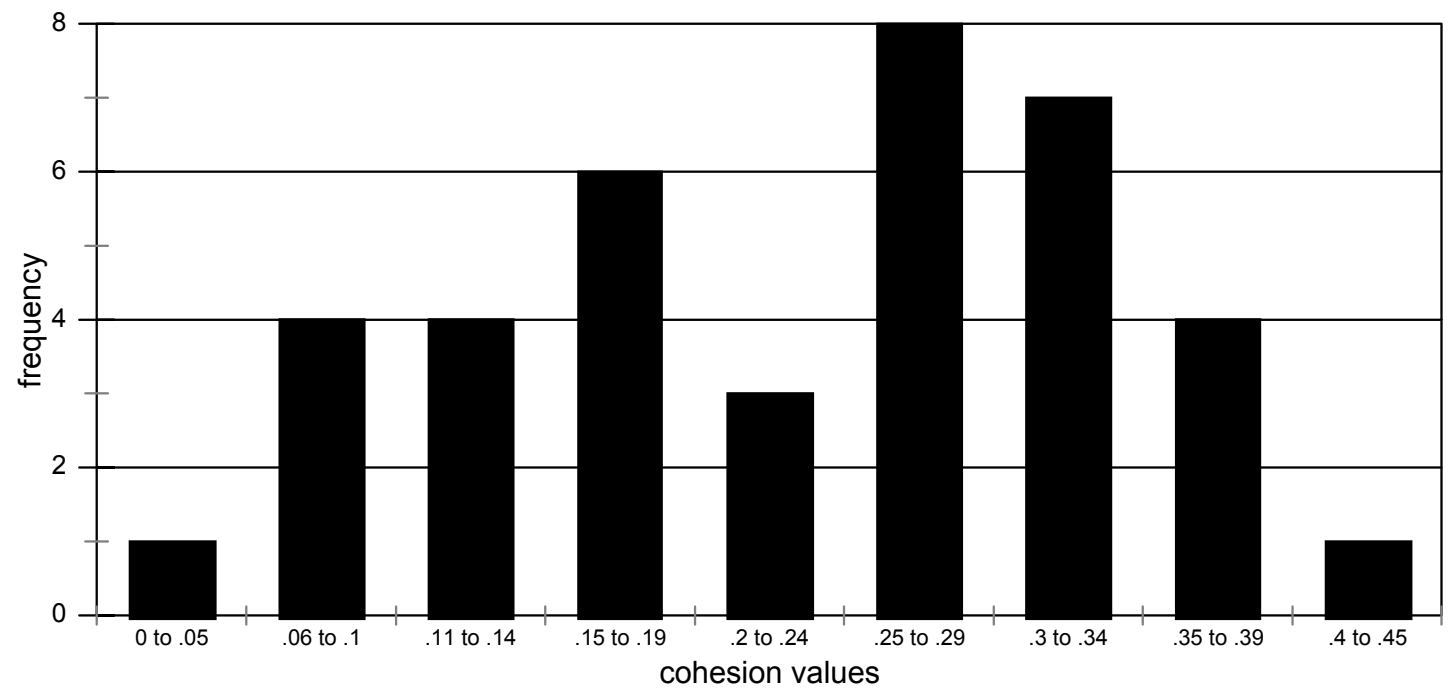


Figure 8: Average Cross-State Cohesion

(38-state sample, 1942:1 to 1995:4, by industry)

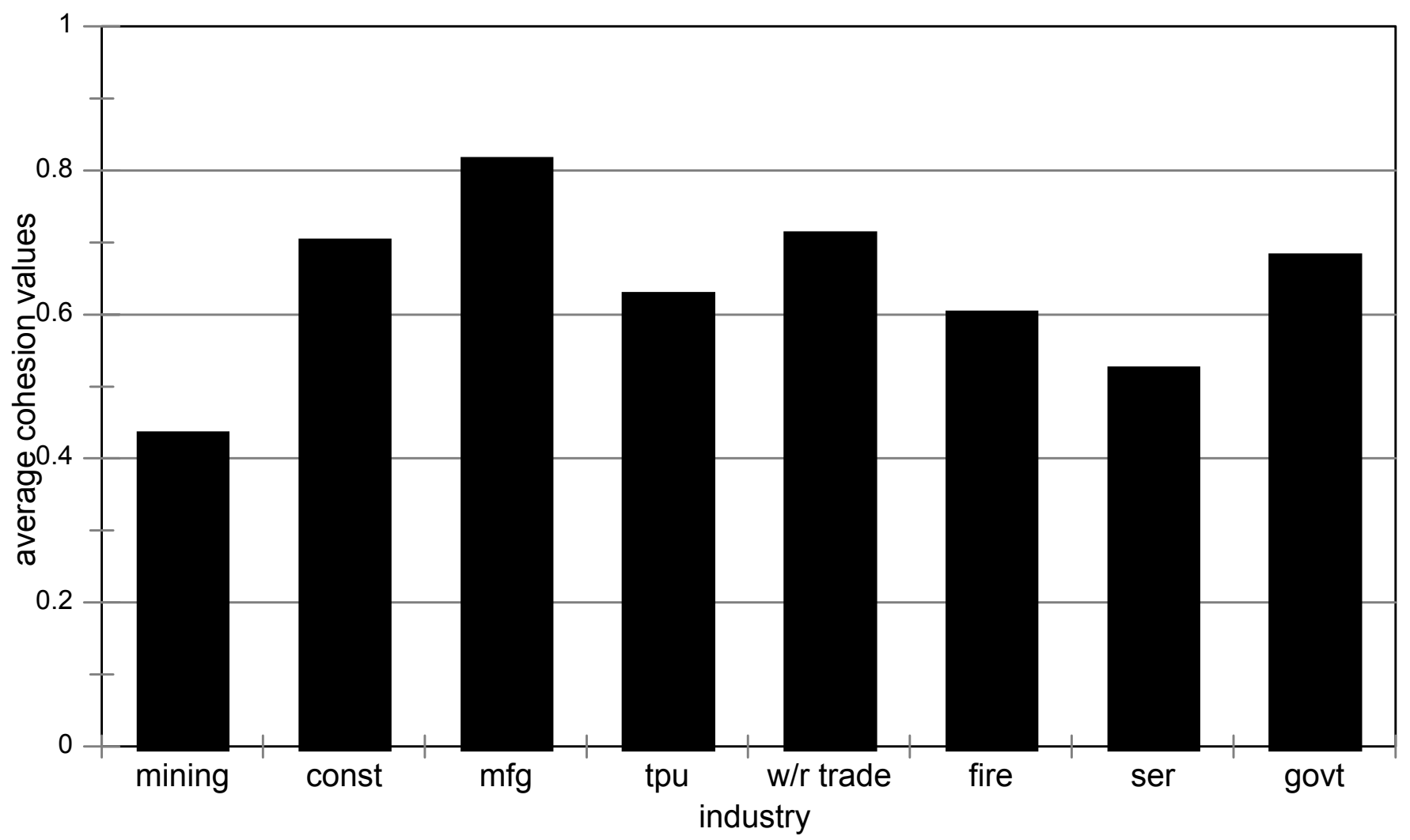

